\title{
Correction to: Student formation in higher education: a comparison and combination of Confucian xiushen (self-cultivation) and Bildung
}

\section{Lili Yang ${ }^{1}$}

Published online: 22 December 2021

(c) Springer Nature B.V. 2021

Correction to: Higher Education

https://doi.org/10.1007/s10734-021-00735-2

In this article the graphics relating to Figs. 1 and 2 captions had been interchanged; the figure(s) should have appeared as shown below. The original article has been corrected.

The original article can be found online at https://doi.org/10.1007/s10734-021-00735-2.

Lili Yang

lili.yang@education.ox.ac.uk

1 Department of Education, Centre for Global Higher Education, University of Oxford, 15 Norham Gardens, Oxford OX2 6PY, UK 


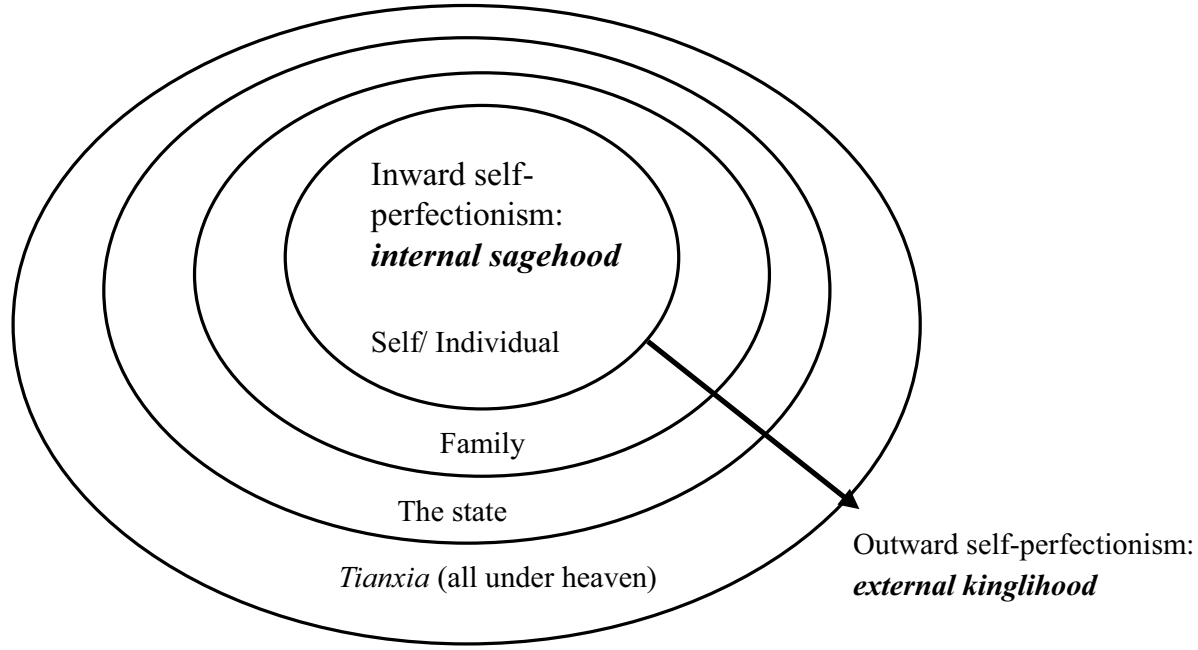

Fig. 1 The expanding entities and xiushen

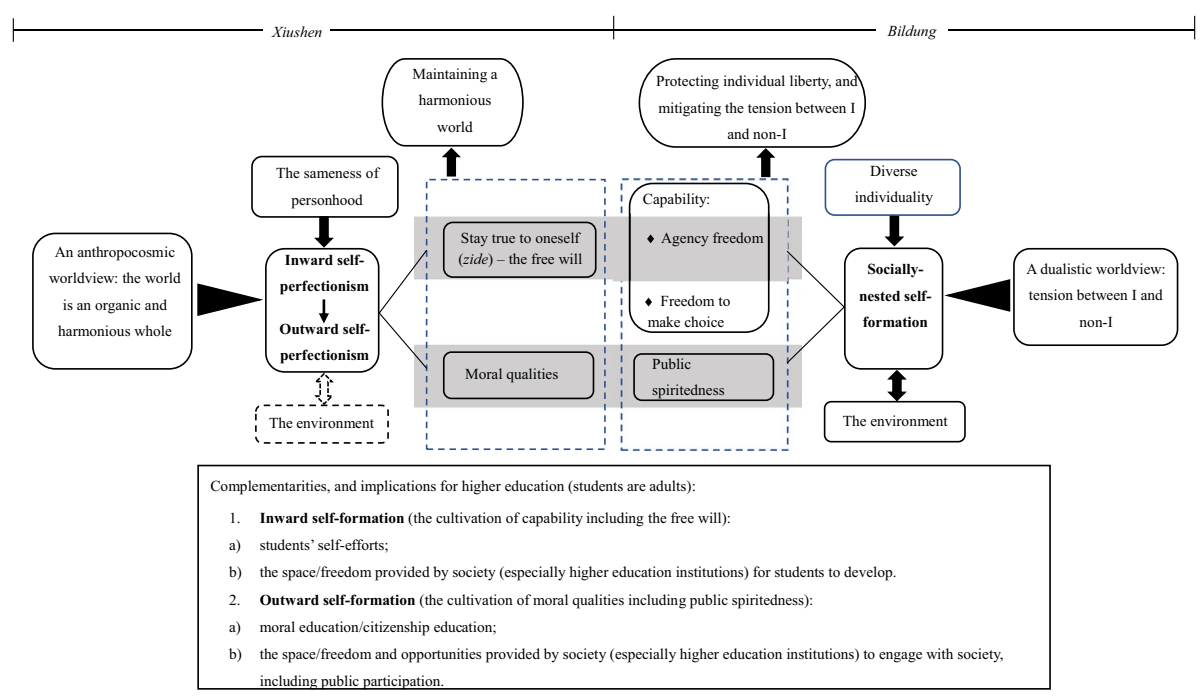

Fig. 2 An outline of the comparison and complementarity between xiushen and Bildung

Publisher's Note Springer Nature remains neutral with regard to jurisdictional claims in published maps and institutional affiliations. 